\title{
FILOSOFIA, EDUCAÇÃO E A QUESTÃO DE IDENTIDADE E DIFERENÇA
}

Damiāo Bezerra OLIVEIRA

Universidade Federal do Pará

Resumo: Nesse ensaio se sumaria a dimensão onto-feo-lógica dos conceitos de identidade e diferença, para em seguida apresentar a crítica do pensanento dialético e da sofistica ao aspecto destacado naquela matriz de pensamento, a fin de mellhor adarar a discussāo atual do tema no campo educacional. Sugere-se que a sofistica antecipa vários elementos que se indnem nos pressnpostos pósmodernos elon pós-estruturalistas no que se refere a teorizaçāo de identidade e diferenga cultural e curricular.

\section{Consideraçōes Iniciais}

Os discursos educacionais têm dedicado, na atualidade, um espaço umpressionante às discussōes sobre os conceitos correlatos de "lentidade e diferença, a partir de uma visada que se poderia chamar frnericamente de antropológica, na medida em que o esforço de ‘mpreensāo se dirige principalmente à questão das identidades c ulturais, da constituição das subjetividades em determinadas relaçōes de poder entre pessoas e grupos nas tramas éticas c políticas.

Pode-se dizer que essa problemática de identidade e diferença coloca-se no interior do que se tem chamado de traclision onto-teo-lígica ‘a filosofia, com conseqüências e reflexos en tudus os domínios da cultura, especialmente nos discursos educacionais yue sion parte desse grande território apresentado como aferidor universal de sentido.

Objetiva-se, pois, apresentar alguns elementos integgrantes dessa tracliço metafísica e as tentativas de refutação advindas do pensanento dialćtico, da sofística e, na atualidade, do que se pode denominar de discursos pósmodernos, sem seguir uma seqüência cronológica rigguros: 11: exposição jâ que o fio condutor do texto é mais temático, argumentativo que narrativo.

\section{A Filosofia e a questão da identidade e da diferença}

\subsection{Aspecto Ontológico}

Nessa discussão estão implicadas problemáticas abertas que vềm 
* cunstituindo, desde as origens do pensamento filosófico, 'mịinto um dos seus desafios emblemáticos. O que se costuma lenominar de princípio da identidade já aparece de modo claro $\mathrm{cm}$ l'armênides, simultaneamente como pressuposto ontológico, do furmsimento e da linguagem.

Da perspectiva ontológica esse princípio coloca-se na idéia de "utuivalência entre unidade e totalidade: "o todo é um" (SOUZA, 1985), A ldentidade opõe-se, pois, à multiplicidade e a nega enquanto tal Un segundo aspecto a considerar diz respeito à exclusão do movimento ou scja, falar de identidade significa a admissão do horror à temporalidade, ì sucessão de momentos.

Assim, identidade seria sinônima de imobilidade, plenitude de presenşa, mesmidade que esvazia a possibilidade da alteridade, de um lugar exterior; na medida em que não há um fora, a identidade é da ordeti do perfeito (téleios) e possui um fim (télos).

A formulação desse princípio aparece em Proclo, reproduzindo o poeta-filósofo Parmênides:

\begin{abstract}
Pois bem, en te direi, e tu recebe (sic) a palavra que onviste os únicos caminhos de inquérito que são a pensar: primeiro, que é e portanto que não é não ser, de persuasdo é caminho (pois á verdade acompanha); o ontro, que năo e portanto que é preciso nāo ser, este, então, en te digo, atalho de todo incrivel; pois nem conhecerias o que năo (pois não é exequiível), nem o dirias... (SOUZA, 1983 p.142).
\end{abstract}

O Ser é igual a ele mesmo e, de modo idêntico, o Não-Ser também se identifica a si mesmo. Esses são domínios que não misturam; entre eles não há qualquer conexāo. O que existe continuará sempre existindo, e o que não possui absolutamente sé jamais o terá.

A preseņ̧a do Ser e a ansência do Não-Ser são absolutas inconciliáveis: o Ser continuará sendo como sempre foi e o Nalo Ser nāo sendo como sempre não foi. Dessa maneira compreendido us dois conceitos em questão não podem ser determinader restringidos na sua abrangência: todas as coisas são, mas nenhumi delas é o Ser; igualmente, todas as coisas podem estar ausentes, mi nenlumuna delas é o Nāo-Ser. 
lindo isso encaminha à idéia de que a ontologia sustenta a iclentulaule ' "' "utunto impossibilidade de o Ser "diferir". Os entes são diferentes c 1'muliplos, possuem essências próprias, mas em nenhum caso a diferença wi.t tida como Não-Ser, contradição ao Ser, mas antes é modo, 111s dialidade do Ser (MOLINARO, 2000) e nele e por ele é que pode tw sentido.

Essa maneira de pensar o Ser coloca a exigência do Absoluto autoIundado que, como tal, pode até estabelecer relaçōes, mas jamais - kejuder de qualquer alteridade para ser o que é. O absoluto é causa e ' 1!̣ cm, perfeição, presença, e tem sido batizado na história onto-teoIn pica com diversas outras denominaçōes, tais como: Deus, Motor lunivel e Bem.

Em função da exposição até aqui feita, pode-se dizer que pensar 1.ulicalmente a relação entre identidade e diferenga consiste $\mathrm{em}$ confrontar "Ser e o Não-Ser. Contudo, em tal relação, somente a identidade seria pritivamente pensável e possível de expressão lingüística, pois o que chlicre absolutamente do Ser, isto é, o Não-Ser coloca-se enquanto o impensável e o inefável: "... pois o mesmo é o pensar e, portanto, ser" (SOUZA. Op. cit., p.142).

\subsection{Aspecto Lógico}

Não se pode separar a dimensão ontológica da identidade c “liferença do seu aspecto lógico. Inicialmente o logos é uma razīo que cngloba, simultaneamente, os entes no seu conjunto e o princípio de unteligibilidade e expressāo dos mesmos,

O pensamento é, antes de tudo, intuição noética, visāo dos cutes na sua essencialidade necessária, e depois expressão dessa experiĉncia .través do discurso, da linguagem. Ora, nenhuma intuição noćtici se daria do que é ausente, logo somente o Ser se revela au pensamentu. Uma vez dado, intuído, ele poderá ser pensado, expressor por um discurso mais ou menos adequado,

O pensamento, a vontade, o desejo e a própria lingn:așcom nйо seriam anteriores ao Ser e por isso nåo the poderiam imper, çualquer forma ou limite, sem o risco de falseamento da ickentidade que deve existir entre Ser c pensar.

Admitida a correção dessa tese, então o corolírio ć çu o Sèr c não o homem é o responsável pela a identidade que se afirma por si mesma por força da sua presença, independente da vontade e dos descjos 


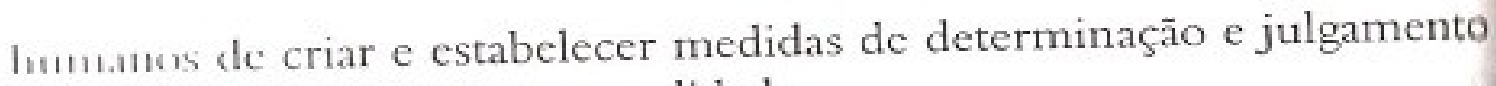
4. ، „ue gostaria que fosse a realidade.

Contudo, se a identidade é a essência do Ser, do pensamento e da Inışuagem que os expressa, ela mesma não é passível de qualquer deliniçāo que não seja uma simples tautologia lógica, como nå iparentemente cômicas formulações de Parmênides que soam hoje como se fossem um mero jogo de palavras: O Ser é o Ser e o Năo Ser é o Năo-Ser. A relaçāo de identidade acima é tautológica porque a única equivalência possível ao absoluto é fazê-lo retornar a si nesmo, pois a predicação desse existente coloca-se como repetiçấ da mesmidade e qualquer restrição diferenciadora implicaria $\mathrm{cm}$ falseamento.

Toda e qualquer predicação que seja feita envolvendo a identidade do Ser, para corretamente expressá-lo, nāo poderá representá-lo acidental, mas essencialmente. Ora, em sendo absoluto, torna-se impossível que na sua definição adequada algo mais figure que ele próprio, umı vez que só a si é inerente necessariamente: o Ser é Ser.

A problemática do Ser desperta a atenção, ainda, para a necessidade de se comparar os termos identidade, igualdade, equivalência e semelhanğ Pode-se afirmar que esses conceitos nảo possuem a mesma significaçló Igualdade, equivalência e semelhança supóem a comparação entri elementos que são, em maior ou menor grau, discerníveis, enquanto identidade, a rigor, se coloca numa relação de mesmidade absoluti Em se considerando a igualdade como uma relação na qual há possibilidade de substituição de um termo por outro, então seriı problemático dizer que o Ser é igual a si mesmo, tendo em vista qui năo se trataria de comparar dois, mas apenas um a si mesmo.

\subsubsection{Lógica da identidade versus lógica da contradiçăo}

A identidade ${ }^{1}$, o princípio de contradição ${ }^{2}$ e do terceiro excluído scrão reavaliados pela dialética moderna. Pode-se afirmar com Rẹ

I Nỉo se podem conciliar duas proposiçōes que afirmem ao mesmo tempo c segundo uAH unesna relaçĩo que algo é e nāo é: esse ế um absurdo lógico por ser uma impossibilidal untukbigica.

Ninma a impossibilidade de duas proposiçóes contraditórias serem ao mesmo tomi verdadciras.

"Nepa que se duas proposiçócs contraditórias possam ser ambas falsas. 
(W, I I: $A N G, 1984$ ) que todo o desafio do pensamento dialético

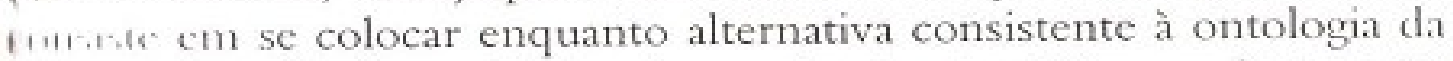
hli utulude, à lógica tradicional, ao método científico moderno e às 1t...1 1.1. da experiência produzidas nesse mesmo período. Interessam injul "lisses aspectos, os dois primeiros.

I l.ıveria realmente uma lógica dialética que não fosse apenas um Eal.... impreciso e crítico, cuja construção se apoiaria na lógica Ilwli isnal como contraponto? A chamada lógica indutiva que se funl.umcntaria nas experiências concretas foi seriamente questionada por Dusul 1 lume que colocou inconsistências até hoje não superadas.

I mbura tal "lógica" permita as descobertas, a inventividade, não ( in. de justificar as suas pretensöes de verdade e nem superar, Hon f.lums da organização e exposição, os princípios da lógica formal, Gư unda sāo, se Popper (1972) tem razão, válidos para se chegar à filaulule de uma teoria científica. Argumentos semelhantes a esse Hil I. vintados contra aqueles que se apegam à possibilidade de uma "lop, a das probabilidades" para justificar os conhecimentos sobre a feiluılıle, a "lógica quântica", ou a "lógica situacional", entre vários

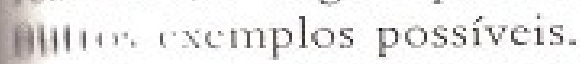

(1) que "defendem uma lógica dialética costumam buscar apoio Haต lı̣̣ı as "quântica" c "paraconsistente", em funçāo de negarem o ham.uls princípio da identidade e aceitarem o princípio da fouradicio. Para Mario Bunge (2002), no entanto, é impensável GHalıuer proposta de lógica que admita a contradição. Ironiza a

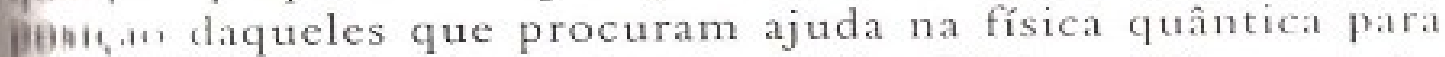
Arfale er a idéia de uma lógica da não identidade, ao dizer que nấo

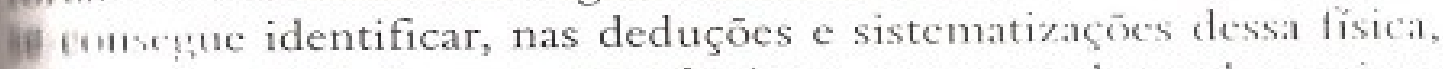
Halıuer vestígio de uma nova lógica a que se pudesse denominar 16 (fuintica.

In razōes semelhantes, nega-se a consistência das propostas que Herem lazer da dialética uma filosofia lógica colocada comos alternativa lopu a firmal e, por conseqüência, as críticas arroladas se cstcucleriam, arrelutıvimente, à ontologia dialética na medida cm que essia fila de flihicle, dinamicidade e contradição da realidade.

A tescente-se que, a dialética hegeliana, bem como a marxista, mbuı pareçam apresentar grandes diferenças, na medicla cm que a ifincu. \& dita idealista e a segunda materialista, náo teriam feito nada

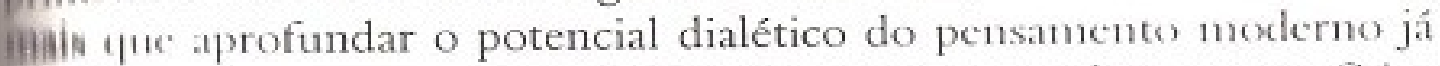
fue tcutut superar os vários dualismos que acompanham a metafísica 
' " ulıt1,.l, '[uais scjam: inteligível/sensível, essência/aparência, interior/ "1etur, dentro/fora, alma/corpo, infinito/finito, materialismo/ whillswese etc.

(isntudo, a identidade faz-se presente no âmago da própria dialética, n.1 medida cm que se busca a unidade, a totalidade, e se procura .umctuizar os efeitos da tragicidade do pensamento ou da ação histórica, ‘u11 i suposição de sínteses sucessivas que conciliariam a tese e a mítesc. A dialética teria acompanhado sempre a metafísica da ulentidade sem conseguir superá-la, desde, pelo menos, a famosa pulimica entre Parmênides e Heráclito nas origens da Filosofia, em torno da contradição maior de todas as pensáveis, que é a que opõe Ser c. Não-ser.

\subsubsection{Dialética: entre a linguagem dialógica e a identidade.}

Na sua origem, no entanto, a dialética diferia bastante do seu sentido moderno e contemporâneo. Surge como um fenômeno próprio dos cntes capazes de interação mẹiada pela palavra em movimento, isto é, pelo discurso que é uma trajetória percorrida pela palavra, corrida de ida c volta de um falante a outro.

Pode-se dizer, portanto, que a dialética nāo ocorre enquanto acontecimento isolado de um pensamento solitário que se constituiria enquanto interioridade, mas como expressāo lingüística, mediaçāo do pensamento que se concretiza enquanto conversa pública.

discurso dialético não é exposição do pensamento, mas antes discussāo e questionamento, a açāo do pensar compartilhado através de perguntas e respostas. Em razão disso é que se chamavam de dialéticos aqueles que mostravam dominar a arte de interrogar e responder.

Sendo assim, não teria qualquer sentido afirmar que a realidade é dialética, pois a significação originária do conceito não é ontológica, unas discursiva. $\mathrm{O}$ movimento dialético ocorre no interior da linguagem, nia cxpressão do pensamento e não é uma representação da dinâmica (li) ser, dos entes.

A discussão dos homens não visa acompanhar as mudanças que se dão n.. realiclade, numa espécie de movimento de atualização; mas só se justifica |xliı ịnorância dos dialéticos do que sejam os entes enquanto são.

^ intruxlução da dialética na filosofia dá-se, a rigor, quando esta ulıı⿰丿⿱丄𠃍, volta a sua preocupaçāo para os problemas humanos, éticos e 
p'siticos, com Sócrates e a sofística. $O$ mestre de Platão irá cncarar o I"usamento como exercício de questionamento, discussão pública das "1lezas sobre o que os entes são, a partir do pressuposto do nāo saber 1.ulical.

Sócrates realiza uma filosofia pública na medida em que coloca as ، ‘tczas em movimento dialógico, através da linguagem oral que cobra . presença viva do outro, a abertura infindável para novas possibilidades ic conxergar a realidade.

Com Platão (1994), haverá certa recusa desse movimento público ds pensamento e a dialética passará a ser encarada como episteme, - Mencia do universal e necessária, no seu mais alto grau. A mediação lııgüística não mais estará na origem do pensar, pois a racionalidade é primciramente "intuição noética", contemplação da rcalidade de modo uncdiato. O movimento dialćtico ocorre no domínio espiritual como msecensāo interior, pessoal em direção à verdade, á perfeição do que "xiste independentemente do pensamento, de qualquer poder wnstitutivo do homem.

Dialética é movimento do pensamento com objetivo de alcançar a calidade. Essa, contudo, permanece inteiramente indiferente no seu scr, a todo esse esforço. Permanece igual a si mestma no seu acabamento, umóvel e estável na sua perfeição e unidade: indiferente ao tempo, à liistória e às açōes humanas.

Assim, a dialética é a epopéia do pensamento que vai se libertando das certezas sensíveis, das opiniōes comuns, do encantamento da linguagem enquanto criadora de realidades para atingir a realidade no domínio das idéias. Contudo, há o movimento de volta: a dialética, que conduz o pensinuento ao mundo inteligível, o traz de volta ao mundo sensível. $\wedge$ alma do filósofo quando desse retorno já não é mais a mesma c, portanto, a sensibilidade já não encara a realidade da nesma maneira. $O$ diálogo e a discussão deixam de fazer sentido após esse retorno, pois a dialética só se justifica no seu antiģos scntido quando há o encontro de "ignorantes". Ora, o filósofo volta da sua viagem dialética, esclarecido do que é a realidade.

Nesse contexto, a comunicaçāo só se cfetua plenamente entre os filósofos, pois as palavras só sāo preenchidas de significados em função das intuiçỏes noéticas. Para aqueles que jamais renovaram tal visão pelo esforço filosófico, as palavras não representarão em todo a sua plenitude, o mundo das idéias. 
^ partir de Platão, a dialética no seu antigo sentido de discussĩo prublicia, passa a ser vista com suspeição, por se entender que ẩ p.ılavras descoladas das intuições da verdade, podem criar ilusôe! " cucintamentos, fabricar verdades fictícias às quais tendem a sceluzir os homens e desviá-los da difícil busca da realidade em ıuc confere significaçāo a tudo. A dialética feita de palavras iclentificada com a sofistica, definida pejorativamente pele platonismo como certa habilidade para fazer o falso parecer verdadeiro e vice-versa, de acordo com os interesses c al necessidades humanas do momento.

Essa possibilidade de mudança dos enunciados, das teses, em funçāo das circunstâncias, representava um grande escândalo para l dialética da identidade defendida por Platão. Para o pensamento desse autor, a dialética conduz à identidade e é, ao mesmo tempo, por ess! conduzida. Durante o diálogo, seria preciso dividir a matéria en pauta, a fim de nâo se misturarem identidade e diferença: necessárï se faz dividir de acordo com os gêneros para nāo julgar o mesmo como outi nem vice-versa.

O princípio que preside a divisão é o da identidade: coerência di pensamento consigo mesmo e com o ser. Embora o pensamento nliti seja capaz de instituir a realidade à sua imagem, o contrário deve acontecer. A identidade gnosiológica deriva da identidade ontológiẹ de acordo com uma compreensão da verdade como representaçĭo di realidade pelo pensamento.

A estabilidade da linguagem num discurso verdadeiro, $c$ umi exigência ontológica: se o que é real não pode mudar c se enunciados representam realmente tal realidade, então é preci que se continuc afirmando uma mesma tese sempre. A dialétic scria, portanto, em Platão, a ciência do que não se movimentı permanece eternamente igual a si mesmo. O seu afä sefi contemplar o absoluto, chegar a um fim último que poria um terie a toda e qualquer real discussão.

Em síntese, a dialética não se pretende, em todas as situaçố incompatível com a ontologia da identidade e pode perfeitament constituir-se enquanto sistema metafísico baseado no princípio da ni contradição do ser, também do pensamento sobre ele, assim como linguagem que o expressa.

Considerados os pressupostos da ontologia, da lógica e mesme comprecusāo de linguagem subjacente à discussão apresentada, eni 
" que se entende hoje como dialética seria identificado à irracionalıd.ıle. . 1 sgicidade e incomunicabilidade.

O movimento, a mudança e a diferenciaçāo só podem ocorrer entre s. determinaçōes do ser e no seu interior. A diversidade e a diferença $\because$ fazem sentido pela unidade. A alteridade do Ser enquanto "cxterioridade" seria o Não-Ser. Mas a alteridade dos entes que se "unstituem no Ser, sāo as diferenças ônticas, que se fundam, por sua vez, na diferença ontológica entre Ser e Ente. A negatividade e a oposição ‘correm entre as determinaçốes do Ser, unidas por esse mesmo Ser. É 1. Ser que garante a unidade dos opostos, fazendo-os retornar à r'gulação do princípio de não contradição.

A tese, a antítese e a síntese, ou movimento processual dialético, parte da identidade (afirmaçāo) e volta a ela, pois a negação da negação $\therefore$ novamente, afirmação, identidade. A negação só ganha sentido pela afirmação e vice-versa. O momento negativo do processo é abstração, o verdadeiro na sua concreticidade só ocorre no momento de síntese, quando se recupera a unidade totalizadora.

$O$ verdadeiro estaria, portanto, do lado da identidade, da unidade do mesmo que subsume a alteridade (INWOOD, 1997, p.172-3). O processo dialético faz-se através da mediação, isto é, por um movinento de passagem ou mais apropriadamente de ultrapassagem do positivo ao negativo e desse a uma nova positividade, prevendo, portanto, um ponto de repouso do pensamento só encontrável na totalidade que porá fim a tragicidade. Se a conclusāo a que se chega aqui for correta, deve-se dizer que a crítica dialética termina por minimizar o papel da diferença, da alteridade, na medida em que essas representam o que precisa ser superado em nome da unidade identitária.

\section{Crítica antropológica e educacional à ontologia e à lógica da identidade}

\subsection{Teoria do homem-medida}

A onfo-teo-logia acima esboçada tornou-se o modelo de ser e pensar na história do ocidente, embora nunca tenha deixado de ter a companhia da sua alteridade negada, reprimida enquanto o que não pode ser visto, pensado, dito ou que deve ser superado.

A crítica emblemática à metafísica da identidade foi levantada pelos sofistas quando, no período clássico, ajudaram a constituir um pensamento filosófico voltado para as grandes questōes humanas 
ke ordem ética e política. A partir daí, muitas outras tentativas de refutaço ao pensamento dominante se seguiram ainda na Antiguidade.

Quem postula de modo mais evidente essa reaçāo crítica ć แm dos mais famosos dos sofistas, Protágoras. É dele a conhecida formulaçăo que teria escandalizado Platāo, de que "o homem é a medidi de todas as coisas, das coisas que são, enquanto são; das coisas que não são, enqualle não são". Com essa tese ele introduz a filosofia na trilha humanista ético-política, mas causa também grandes discussôes teóricas que jamais se apagaram.

No passado, como hoje, discute-se o sentido dessa tentativa radieal de humanismo (JAEGER) e até de justificação teórica da vida democríliei (WOLF). Gilbert Romeyer-Dherbey (1986) destaca os termos grego centrais da formulação sofística para buscar na sua riqueza polissêmiea. uma interpretação possível. Os conccitos que têm atraído os estudioso: Sāo: pragna, chrena, métron, ánthropos.

Qual sentido atribuir ao termo ánthropos? Para o autor já referido pode-se interpretá-lo, como significando de sujeito singular, mas tambéa homem genérico (ABBAGNANO, 1992). Por fim, é possível entende ter sido a intenção de Protágoras jogar semanticamente com a linguagen ao atribuir ao conceito um sentido flutuante, podendo, portanfo significar tanto o homem na sua singularidade quanto na sua condiẹic genérica, simultânea e sucessivamente.

Mesmo sem saber qual a interpretação mais plausível, possível identificar a antropomorfização da verdade. Ela ser completada com a interpretação do termo métron, portador de uni ambigüidade cujos sentidos são passíveis de complementação cnti si, pois dizer que o ánthropos é o métron pode significar: transforma o homem em critério do que é ou do que năo é existente, do que valioso ou não, isto é, fazer do homem a fonte ontológica, axiológie e gnosiológica de tudo. Complementamente se pode afirmar qui ser métron é dominar, ou seja, exercer o poder, fazer valer a vontad c a decisão sobre as coisas. O segundo sentido da interpretaçăo mais claramente político.

Diante disso, fica a grande inquiriçāo: essa visão antropológica homem-medida estaria circunscrevendo o seu campo de validade diminio das "coisas humanas"? Haveria um outro domínio do qual huncm não scria a medida? Haveria realidades e verdades diferent de acordo com a relação que os homens mantêm com os entes? 
() S herdeiros mais imediatos dessa razão sofística sāo os cépticiss 'll' se seguiram, os Epicuristas e os Estóicos, no contexto da crise da hlimofia grega antiga após o esplendor dos pensadores clássicos. De .untelo com Nicola Abbagnano4, a preocupaçāo maior dos pensadores I'."s aristotélicos é com o mundo prático, mais especialmente com a 1. liciclade e menos com as grandes questões ontológicas.

Esses autores buscarāo inspiração no heraclitismo e na sofística, 1...firmando uma visāo dinâmica da realidade, em contraposição aos puncípios ontológicos da razão identitária. Criticam e argumentam untra o antigo desejo filosófico de chegar a um fundamento isento 4. qualquer refutaçāo. Negam mesmo a possibilidade de tal lundamentação "natural", reafirmando que a questão da verdade prıssa pela convencionalidade e que é preciso suspender o juízo ou :uhmeter à indagação (skêpsis) tudo que diz respeito à essência ou ao $r m$ si da realidade, pois tudo é sempre para o homem. Defendem a use segundo a qual a verdade como os valores se colocam na Acpendência de certa convencionalidade cuja origem imediata é o - wstume. Frente ao que seja a realidade em si, por natureza, só resta suspender o juízo. A tal atitude epistemológica eles denominaram dce epochê.

Tomava-se como método para mostrar a inconsistência do princípio ac identidade, as famosas antinomias ${ }^{5}$ e também os paradoxos e dilemas ainda hoje comentados, cujo objetivo era mostrar a possibilidade de afirmar, com igual força, teses contraditórias sem que se pudessem apontar critérios constrangedores que permitissem ao homem decidirse por uma ou outra tese. Com isso se pretende mostrar que fora da convencionalidade inexistem critérios para se cheģar a dizer claramente, delimitar de modo peremptório o falso e o verdadeiro. 1)esloca-se a questão da verdade do âmbito da faculdade raciomal ( $A$ BBAGNO, p. 54), para o âmbito da vontade e da decisão, deșuralificando igualmente a sensibilidade como fundamento último,

\footnotetext{
"Aqui se mostra a influência de Heráclito que valorizava uma ontologia "trágica" na qual a realidade cra vista como feita de contradiçö́cs e tranadia em constante movimentaçio, ao contrário da ontologia identitária pregada por Parménides.

3 Carnćades teria admitido que subjetivamente é possível viver uma representação como digna
de crédito, isto é, portadora de credibilidade, portanto, poderia ser chamada de perstasiva até que fosse contradicada por de credibilidade, portanto, poderia ser chamada de persuasiva até que fosse contraditada por represcntaçôes portadora de maior probabilidade de ser verdadeira.
}

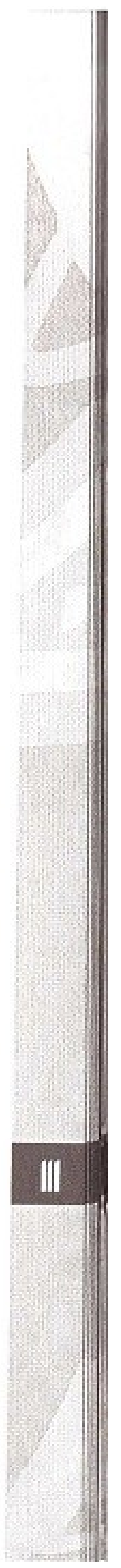


Na basc do ceticismo, segundo Abbagnano ${ }^{6}$ tem-se certa visão de homen enquanto individualidade cujas faculdades tendem a sentir de แ11 unulo próprio e idiossincrático, impedindo uma relação unívoẹ ‘ sıu a rcalidade. Além do que, argumenta-se, há outros seres capaze dic representar o mundo, e o modo como representam precisa servil d. comparativo para o homem. Acrescente-se o princípio da diferenge cutre os homens e sua maneira de sentir; a novidade das diveran circunstâncias pessoais e espaço-temporais; por fim, é preciso atentị quc a verdade está na dependência dos diversos tipos de educaçāo e de costumes, das leis e crenças adotadas pelos povos, bem como dil opiniōes cristalizadas.

A tese protagoriana e cética do homem-medida opor-se-á, portant à de Platão para quem o conhecimento necessita ter por medida Deil ou o Bem, critério não humano, absoluto e por isso imune às mudanty constantes verificáveis no mundo da vida comum e cotidiana. Assilit cmbora o homem, enquanto filósofo, scja o responsável pelo o anúne da realidade, ele o faz constrangido pela evidência da mesma c jamais pi ato de decisão ou de vontade própria.

Platão entende que o conhecimento é representacional (SOU/ 1985), de modo que deve haver uma correspondência cntre enunciados e os objetos aos quais ele remete. A opiniāo (doxi) semelhante aos objetos do mundo sensível, e nessa condição define pela mutabilidade e multiplicidade. A lógica da identidade que sustentin ontologia clássica mostra a total impossibilidade de conceder autonen c real existência ao chamado mundo sensível.

Discursivamente, o mundo sensível se expressa em proposiç contraditórias, paradoxais e dilemáticas, pois essa é a representi possível de um mundo mutante, múltiplo e sem autonomia ontoló São essas formas de expressão lingüísticas não lógicas c ọil figurativas e metafóricas que melhor representam as diferenęa scu livre jogo sensível.

$\mathrm{O}$ que Platão critica, a sofística acolhe positivamente. $\mathrm{O}$ livre sensivel recupera a tragicidade diferenciadora do tempo, libertaec suas continuidades, do seu caminhar reto em direçāo a um télos afêi de sentido. Mais do que reconhecer o tempo como passado, pre

\footnotetext{
" I loje se postula uma crise geral da representação, tanto no ámbito epistemológles fulisus, por se entender que tal noção faz parte de uma filosofia do sujeito.
} 
- Inturo, como uma série de antes, durante e depois, a tentativa du alistas de explosāo da ontologia iria embaralhar os instantes, mustur.ur. mvirter e subverter as seqüências.

Algo de semelhante ocorreria ao espaço, uma vez liberto da .untulogia da identidade. O Ser entregue ao espaço qualitativo, passaria t clilerir ao sofrer a ação das condiçôes climáticas, sociais ou culturais; - laria entregue às forças das circunstâncias, aos acidentes geográficos 1. is imprevisíveis mudanças da paisagem.

Portanto, há na Antiguidade, duas propostas para pensar a wirutidade e a diferença que estarāo alimentando, historicamente, a Irscussão dos filósofos. Os sofistas serão reabilitados, depois de virios séculos, por pensadores como Nietzsche na sua luta pela Hemolição da ontologia clássica e estarāo na base de muitas propostas , que os racionalistas mais clássicos classificam de irracionais. São u'sponsáveis também, por grande parte da argumentação que tem sustentado a chamada consciência histórica, social e cultural modernas.

\subsection{A questão da identidade e da diferença na Educaçăo}

Embora a recusa da metafísica como um todo esteja na base das tcorizaçōes sobre a identidade e a diferença na educação, dificilmente sc chega a explicitar o que se está rejeitando. Daí porque a primeira parte do presente trabalho procurou expor, ainda que sumária e dogmaticamente, alguns aspectos centrais da compreensão metafísica dos dois conceitos contra a qual se insurgem os críticos e algumas das tentativas de refutação no campo da filosofia.

$O$ interesse atual das pesquisas e reflexões educacionais pelos conceitos correlatos de identidade e diferença, conscientenente ou nâo, retoma aspectos da crítica inaugural dos sofistas c céticos à metafísica, atualizada, evidentemente, por pensadores que já fizeram ou fazem essa mediação, como é o caso de Nictzsctuc, crítico de Parmênides ${ }^{7}$ e Platão e admirador confesso da filosofia maldita dos sofistas e do trágico Heráclito, e do pós-estruturalismo francês (BURBULES, 2003).

\footnotetext{
7 Também se costuma enquadrar Michacl Foucault, Jcan-François I.yotard, Roland Barthes c especialmente Gilles Deleuze e Jacques Derrida no denominado "pensamento da diferença".
} 
I's+14.1140, sc a crítica à chamada metafísica ocidental e aos scus 111114 1p-11s pressupostos não se constitui em novidade na história da l, $1, \ldots+1,1,110$ campo educacional, de acordo Burbules ${ }^{8}$, é emergente a $.11+11.15$ ín desse arcabouço através da literatura pós-moderna e/ou I"* cstruturalista, especialmente através da versão dos estudos culturais.

l'urbules" reconhece as dificuldades conceituais que a reflexão uprescutil para as teorias educacionais e curriculares, e sem objetivar a -xumstividade, apresenta o que seria uma gramática da diferença, em que asse conccito é classificado como variedade, variação, gradualidade, versão, whulogia, diferença além, diferença no interior e diferença contra.

Após caracterizar ${ }^{10}$ o que seria cada um dos tipos de diferença, o antor citado encarrega-se de efetuar uma autocrítica à sua tese, pois cmbora nāo use a palavra identidade, tem consciência de que os cinco primciros termos da sua classificação pressupōem algum tipo de quadro fixo ou estrutura que suportam e concedem sentido à diferença, o que coloca tal taxionomia, acrescentar-se-ia aqui, de algum modo sob o domínio lógico e ontológico da metafísica.

Na tentativa de libertar-se da clausura do enquadramento categorial da sua classificação, Burbules acredita que os três últimos termos, diferença além, no interior e contra superariam os limites dos cinco primeiros, pois com cles se poderia encontrar a diferença num estado pré-categorial.

Algumas ponderaçōes sāo possíveis diante dessa tentativa de pensar a diferença na educação de um modo tão radical. De que mancira se pode colocar um conceito relacional sem o seu correlato? Ao se fazer da diferença um acontecimento précategorial, aquela é colocada numa posição de anterioridade linguística ou até fora da linguagem, portanto, como algo que é surpreendido na sua inteireza e pureza singulares e irrepetíveis.

Pode-se dizer que, de fato, a diferença sem correlato só se apresentaria enquanto algo précategorial. Mas afirmar isso é admitir colocar-se no domínio do que nāo pode ser apreendido ou expresso pelo pensamento, pois tanto a identidade é impensável sem a diferença

\footnotetext{
"Iclem, ibidem.

" l'ara acompanhar a definição de cada clemento dessa tipologia que, por questăo de espaço 1 à serí aqui desenvolvida suficientemente, remetemos o leitor à obra citada de Burbules.

"' (A. WOODWARD, Kathryn. Identidade e diferença: uma introduğăo teórica e conceitual. In: SIIVA, limmaz Tadeu da. (org) Identidade e diferenga: a perspectiva dos esfudos culturais. Petrópolis, RI: Hilista Vozes, 2000. O autor acima referenciado parece concordar com a idéia de scoustativielate de identidade e diferença.
} 


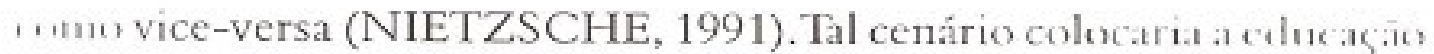
1 "surrículo fora da linguagem, do diálogo, de qualquer identificaşu 1:11p:al ou cultural, pois singularizaria de tal forma a diferenç, а риин te aprisionar cada indivíduo numa clausura solipsista.

Pensar a diferença como précategorial é realizar um movimeutu mriconceitual, já que, no seu sentido metafísico, o conceito é uma นuşa que comprime e depura a existência até que só reste o núclco „wnum e geral. Mas é, também, negar as relaçōes diferencias que 4 u urrem na linguagem vista enquanto uma inscrição desacompanhada A.ı intuição e da presença de uma consciência interna que conferc : totido.

Uma pedagogia da diferença que aceita esses pressupostos é uni, ante e também contraconceitual, pois, contrariamente à propensāo identitária da metafísica a fixar a essência, ela procuraria de's-identificar, isto é, procuraria no que se apresenta como idêntico, "' diferencial, isto é, os processos de diferenciação e as relaçōes de wher-poder que os acompanha. Des-identifcar, nesse sentido, seria lıberar a diferença pela desnaturalizaçāo, explicitação da gênese t'mporal das identidades: raciais, sexuais, de gênero etc. Assim, lesmascarar-se-ia a identidade, ao mostrar a sua procedência histórica, a artificialidade das essências que longe de se sustentarem numa intuição pura e isenta, são fábulas (HALL, 2001) cuja continuidade se garante pela vontade que se afirma em certas rclaçōes de força e/ou de astúcia.

Enquanto Burbules escolhe o termo diferença como central para se pensar uma educação multicultural que supere os ideários liberais mais clássicos e conservadores de educação, Stuart Hall (DUCROT c TODOROV), com propósitos semelhantes, elcge a palavra ideutidade como chave de uma compreensão da situação cultural na pósmodernidade.

Para os propósitos desta abordagem, serão examinados de que modo esse autor compreende a identidade e a diferença. Na obra cm análise inexiste discussão clara dos dois conceitos, mas se percebe que o foco é pensar a fragmentação da identidade, a sua proliferação, de modo que nāo se pense mais uma identidade, mas $\mathrm{cm}$ diferentes, contraditórias e móveis, identidades convivendo sujeitos fragmentados na modernidade tardia.

Numa comparação com Burbules, verifica-se que a concepçāo de Hall é categorial, pois se apóia na idéia de pertencimento dos 
sijcitos a culturas específicas que servem, de algum modo, de refercncial identitário que antecedem o processo de diferenciação. Cimtudo, categorias como raça, etnia, língua, religião e nacionalidade s.11 vistas como móveis e contraditórias e são postas num "jogo de whutidades" que ocorre nos sujeitos, desestabilizando-os constantemente, sem que qualquer das múltiplas identidades adquira (1) status de referencial maior para avaliação das demais. Apesar da imprecisāo conceitual, Hall sugere que o movimento de difcrenciação atua entre as identidades categorizadas, mas também 110 interior dessas categorias.

A recusa à metafísica clássica aparece na crítica à idéia de sujeito como possuidor de um núcleo essencial que o identificaria. As identidades colocam-se, antes, no plano do que é acidental e contingente, dependendo das mais diferentes circunstâncias e contextos. As diferenças não são entes naturais, mas construções e representaçôes convencionais no sentido dado por Saussure ao termo convenção" ao se referir a língua como um sistema; quanto à idéia de representação $\mathrm{e}$ de linguagem, os referenciais são autores como Lacan, Althusser, Foucault e Derrida, na medida em que eles permitem que se compreenda a linguagem como ato de fala ou de discurso e não como simples instrumento de re-apresentação isenta e realista de uma realidade dada em sua essência e intuída como tal.

Os dois autores referidos estāo próximos da tese protagoriana do homem-medida na inadmissāo de que o mundo cultural (nomos) possa ser compreendido por uma ontologia que pregue a existência de qualquer essência universal e necessária, notas da identidade metafísica.

Trabalham com a margem de imprecisão que faz do ánthropos sujcito individual ou grupo mais ou menos numeroso, definidos flexivamente por critérios culturais (nomos) e não biológicos (physis). As categorias raça/etnia, sexualidade, gênero, nacionalidade c classe não sāo puras nem naturais. São classificações identificadoras que se estabilizam e desestabilizam por convençōes que dependem mais da

\footnotetext{
" Alpuns teóricos pós poderiam acrescentar mais um elemento a essa polissemia, questionando "h humem-medida enquanto individuo do sexo masculino, branco, heterossexual, europeu, "15. 13 cte. e que tem sido historicamente a "medida de todas as coisas", sob vários aspectos. O duhlurogras dors sofistas permite que se faça todos os descentramentos e fragmentaçócs até se Clu'vil a 11 a medida de todas as coisas absolutamente singular c solipsista.
} 
nurrale ou do poder do que de consensos racionais com base em verdade unuitivas e fixas anteriores à linguagem.

Se tudo isso for correto, entāo a pedagogia da diferença nasce como fmsibilidade na sua própria origem sofística, na medida em que os upresentantes desse pensamento postularam a importância de uma "Iilusofia" da relação contingente na qual conta mais a vontade walizadora do que a razão teórica e contemplativa.

Foram eles também que descobriram a capacidade da linguagem, 11.10 de representar a realidade e traduzir pensamentos, mas de "wnstruir" e apresentar diferentes identidades. Ensinaram com isso ‘1u a educação é atividade de construção da vida enquanto "nomos" ‘uc se pode fazer- desfazer-refazer ao sabor das contingências. Foram ‘ precursores, portanto, da relação inseparável entre linguagem, s.tber e poder.

Num tal cenário, o homem-medida (SARTE, 1984, p.18) seria, l.ız-se necessário admitir uma medida extremamente móvel e mutável, pois a falta de uma essência do homem desestabiliza qualquer critério cxterior ao movimento da existência. Se os sofistas, pós-modernos e assemelhados estão corretos, então a atividade educacional e a situação dos homens no mundo teriam que ser pautadas por algo como a recomendação sartreano para os existentes que vão construindo, sem nunca completar, a sua essência:

Digamos antes que devemos comparar a escolha moral ì construção de una obra de arte... Alguma vez se acuson um artista que faz um quadro de ele näo se inspirar em regras estabelecidas a priori? ... O mesmo acontece no plano moral. $O$ que há em comm entre a arte e a moral é qué, nos dois casos, existe criağäo e invenşăo.

Muito embora o objetivo argumentativo de Sartre seja bem específico, está em jogo uma mesma crítica à metafísica, à idéia de essência fixa. Se não há regras a priori, um dever-ser do homem para além das suas decisões na existência situada c concreta, entāo resta ao homem instituir a sua existência, individual ou grupal, como criação e invenção.

Também em Sartre os sujeitos não possuem uma identidade, pois nega a noção de natureza humana. Mas isso nâo o impede de sair do solipsismo a que tendia pela centralidade concedida ao eu penso. Se for 
verdiale que o homem não possui essência anterior à sua existência nc-u se completa jamais enquanto vive, deve-se admitir, ao menos unı: rondição humana comum que permite a intersubjetividade e romunicação no decorrer do tempo.

'lalvez os teóricos da pós-modernidade precisem pensar mai profundamente, como fez Sartre, nas conseqüências decorrentes di nçuação de qualquer essência ou natureza humana, a fim de tornạ mais consistentes as suas posiçōes.

É preciso pensar, sim, no problema de um mundo intersubjetividade, pois se se quiser pensar a educação, as prática curriculares, os processos de ensino e aprendizagem e os conteúdo curriculares, nāo se pode impunemente deixar de reconhecer indispensabilidade da comunicação, da troca de argumentos, de qualque ponto de comensurabilidade. A diferença seria, pois, impensável ou indiferente se admitida num fechamento singular: é preciso ser dita vivida no plural, mesmo que isso implique tensão permanente c sem sintese.

Uma pedagogia da diferença seria sofística e trágica, pois nít objetivaria criar pontos de repouso comum-unitários, consenso amplos e duradouros com a finalidade de acomodar a força pulsante das diferenças, embora não se deva cultuar a violência física cul exemplo privilegiado é o terrorismo, mais até que a guerra. Exiśt uma tentativa de afirmaçāo da diferença na ação terrorista qui explode de um lugar solipsista e mudo no qual a alteridade na pode co-habitar

É preciso pensar nos perigos das diferenças que querem se afirmai absolutamente, pois acabam por se subverter em destrutivas identidade que não consideram a vida enquanto horizonte. Afinal, o complet domínio de Dionísio sobre Apolo é tão prejudicial à vida como vice-ver

\section{Considerações finais}

Nesse ensaio se pretendeu apenas destacar alguns pontos que forant clcitos como pertinentes na discussão da identidade e diferença. Partiu (la exposição onto-teo-lógica dos conceitos na metafísica clássica, pit cm scguida, sumariar a tentativa de refutação do pensamento dialéti c mostrar a insuficiência dessa crítica, na medida em que o seu horizoni acal a por revelar que se deseja atingir, como a metafísica, a identidade a totalidade numa síntese final. 
Sendo assim, a dialética como hoje é entendida na cducaşo n... fueleria sustentar uma pedagogia da diferença, a menos que a .llsridade seja entendida como aquilo que se objetiva superar no tural de um processo teleológico de posiçāo, negaçāo e negação da ưş̣ação.

A sofística pareceu mais consistente na crítica à ontologia clássica pur năo procurar conciliações e assumir as conseqüências trágicas, isto $\therefore$ os dilemas, paradoxos e tensôes advindos da sua refutaçāo da identidade. 1):í a aproximação que se procurou efetuar entre a sofística e k-terminadas posições céticas da antiguidade, por um lado, e os discursos pós-modernos e assemelhados por outro, nas convergências ' luc apresentam na recusa à metafísica.

De uma perspectiva da linguagem e do conhecimento, para a wfística, o sentido de um enunciado qualquer define-se nāo exatamente prelos os elementos conceituais internos ao mesmo, mas pelas condiçōes pragmáticas de sua produção, como o espaço e tempo determinados, urigem social do emissor e dos receptores visados, interesses cconômicos e emocionais e tipo de organização cultural.

Assim, a força de uma argumentaçāo e a evidência dela derivada são função de uma determinada lógica social, datada temporalmente e circunscrita espacialmente. Justifica-se esse modo de compreensão afirmando-se inexistirem quaisquer estruturas racionais a priori, de modo que todo conhecimento teria origem nas relaçóes sociais historicamente travadas pelos homens.

Essa visão como as pós, que valorizam o subjetivismo c o rclativismo cognoscentes e axiológicos, possui enorme importância prática, ética c política, na medida em que tem favorecido historicancutc as organizaçōes sociais democráticas e permitido a refutação des discursos racistas discriminatórios, totalitários e absolutizantes, especialnente no âmbito educacional.

Por fim, se deve esclarecer que, considerando a complexidade c amplitude do tema aqui tratado, reconhece-se a feişón esquemática que o texto acabou por adquirir. Os principais argumentos apresentados, não puderam ser devidamente aprofundados e valem mais como um convite à problematização. Concxōes e confrontos entre as partes do texto tornariam mais claros e consistentes os objetivos e intençōes do escrito. Apesar dessas limitaçōes e mesmo da dependência do texto para maior clareza da consulta às referências feitas em notas, pensa-se que pode ser tomado como 


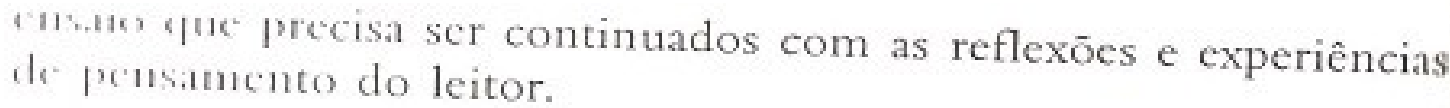

\section{BIBLIOGRAFIA}

ABIBAGNANO, Nicola. História da Filosofia. Lisboa: Editorial Presença, 1992. ARISTÓTELES. Tópicos; dos argumentos sofísticos. Sāo Paulo: Nova ciultural, 1991.

BUNGE, Bunge. Dicionário de Filosofia. São Paulo: Perspectivas, 2002. I3URBULES, Nicholas C. Uma gramática da diferença: algumas formas "ke repensar a diferença e a diversidade como tópicos educacionais. In: GARCIA, Regina Leite \& MOREIRA, A. F. (Orgs.). Currículo na contemporaneidade: certezas e desafios. São Paulo: Cortez, 2003.

DUCROT, Oswald; TODOROV, Tzvetan. Dicionário enciclopédico das ciências da linguagem. São Paulo: Ed. Perspectivas, 1988.

JAEGER, Werner. Paidéia: A Formaģāo do Homem Grego. São Paulo: Martins Fontes, 1989.

HALL, Stuart. A Identidade Cultural na Pó-Modernidade. $5^{\mathrm{a}} \mathrm{ed}$. Rio de Janciro: DP\&A Editora, 2001.

INWOOD, Michael. Dicionário Hegel. Rio de janeiro: Jorge Zahar Ed., 1997, MAIre, Gaston. Platāo. Lisboa: Edições 70, 1986.

MOLINARO, Aniceto. Léxico de Metafísica. São Paulo: Paulus, 2000.

NIETZSCHE, F. Sobre verdade e mentira no sentido extra-moral (Obras Incompletas). $5^{a}$ ed. São Paulo: Nova Cultural, 1991.

PLATÃO. A República. Bauru: EDIPRO, 1994.

20 POPPER, Karl. A Lógica da Pesquisa Científica. $2^{\mathrm{a}}$ ed. São Paulo: Editora Cultrix, 1972.

ROMEYER-DHERBEY, Gilbert. Os Sofistas. Lisboa: Ediçōes 70, 1986. SARTRE, Jean-Paul. O existencialismo é um humanismo. São Paulo: Abril Cultural, 1984.

SIIVA, Tomaz Tadeu da. (org.). Identidade e diferença: a perspectiva dos estudos uluturis: Petrópolis: Editora Vozes, 2000. 
A $11 \%$, José Cavalcante de (Seleção de Textos). Os Pré-Socririros: linuminlos, doxografia e comentários. São Paulo: Abril Cultural, 1985 (C)il. (1. I'nisadores).

Wu 11 1: Francis. Filosofia Grega e Democracia. Discurso: Revista do I " p.ulamento de Filosofia da FFLCH da USP no ${ }^{\circ}$. 14. São Paulo: Editora Pilli, 1983.

W( ) I: ( iANG, Röd. Filosofia Dialética Moderna. Brasília: Editora da UnB, 1014:

Artigo recebido no dia 16 de janeiro de 2005 e aprovado no dia 28 de abril de 2005. 